\title{
COMPARISON OF GEOSYNTHETIC MATERIALS AS SUBSTRATES ON COASTAL STRUCTURES - GOLD COAST (AUSTRALIA) AND ARABIAN GULF
}

\author{
Bobbie Corbett ${ }^{1}$, L. Angus Jackson ${ }^{1}$, Timothy Evans ${ }^{1}$ and Simon Restall ${ }^{2}$
}

\begin{abstract}
Coastal structures should be designed to minimize the risks to beach users and avoid negative impacts on the marine environment. Past experience with sand-filled geotextile containers in the marine environment (i.e. submerged) shows that they provide a permeable substrate that supports a diverse range of marine growth which differs from that found on conventional "hard" structures. To quantify the potential benefits, comparative trials between different geosynthetics at different depths have been undertaken in both in the hot high salinity waters of the Arabian Gulf [UAE] and in the sub-tropical waters of the Pacific Ocean [Gold Coast, Australia]. Results indicated that high strength non-woven type geosynthetics are most suitable for structures which are intended to provide ecological / recreational benefits as they provide higher diversity and less hard growths which are not as user-friendly.
\end{abstract}

Keywords: geosynthetic, geotextile, substrate, ecology, marine growth, recreation, sand-filled geotextile containers

\section{INTRODUCTION}

Coastal structures should be designed to minimize the risks to beach users and avoid negative impacts on the marine environment (Jackson 2010). Past experience with sand-filled geotextile containers in the marine environment (i.e. fully submerged) shows that they provide a permeable threedimensional substrate that supports a diverse range of marine growth which differs from that found on conventional "hard" structures. This was clearly observed during monitoring on the Narrowneck artificial reef (Gold Coast, Australia) as well as a number of semi-submerged breakwater, reef and groyne projects in the Arabian Gulf. This has lead to the recognition that coastal structures have the potential to provide environmental benefits as well as associated recreational opportunities such as snorkeling / diving. These objectives can be included in the engineering design process. There is a wide range of high strength engineered geosynthetics available for use in coastal structures and this paper investigates and compares the marine growth that is supported by various geosynthetics under a range of conditions.

\section{BACKGROUND}

The first detailed monitoring and research into the marine habitat associated with SFG structures was carried out at the Narrowneck reef on the Gold Coast, Australia (Jackson et al. 2004). This is a Multi-Functional Artificial Reef (MFAR) designed to provide coastal protection and improved surfing. After construction in 1999, monitoring showed that an extensive marine habitat had been unexpectedly created and the reef also provided positive environmental benefits.

The thick needle-punched non-woven geosynthetics used in the construction of this reef provided a porous surface for the embedding of sand and growth of a wide diversity of marine flora and fauna [Jackson et al. 2004]. Observations by the Australian National Marine Science Centre indicate that "the biological communities associated with Narrowneck Artificial Reef appear to enhance biodiversity and productivity at a local scale and may also contribute to overall regional productivity.” (Edwards 2003). It was also noted that the species communities are substantially different to other natural reefs in the region with the presence of resident (benthic and demersal) fish and other species, such as juvenile prawns, abalone, turtles, lobster that are not generally observed on nearby natural reefs that were monitored to provide comparative data.
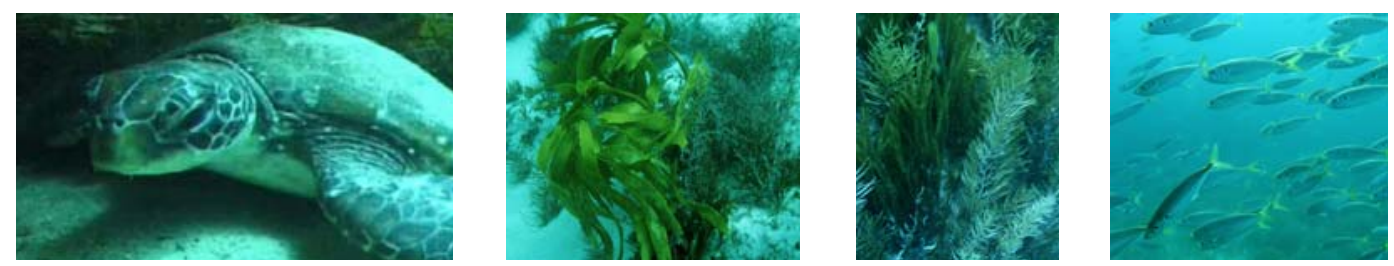

Figure 1. Turtles, kelp, long algae and scad at Narrowneck artificial reef

\footnotetext{
${ }^{1}$ International Coastal Management, PO Box 7196, Gold Coast MC, Queensland, 9726, Australia

${ }^{2}$ GSR International, Gold Coast, Queensland, 4216, Australia
} 


\section{TRIALS}

A number of different geosynthetics were utilized on the Narrowneck reef project and it was clear that there were differences in terms of the ecological development. Previous testing has been undertaken comparing different geosynthetics, however their applicability to other locations and conditions was unknown. As part of preliminary works on a number of projects, trials have been undertaken comparing different geosynthetics in both the hot, high salinity waters of the Arabian Gulf [UAE] and in the sub-tropical waters of the Pacific Ocean [Gold Coast, Australia]. Investigations have also been structured to provide some insight into the potential impact of water depth and water flow on growth.

Given the nature of the testing undertaken, general qualitative assessment of results is possible, however a range of different factors were investigated (water depth, location, geosynthetic type) and there were not sufficient samples for replication and as a result full statistical analysis of results is not possible. The findings do, however, provide good indication of general results and behavior over a relatively long time period.

\section{UAE TRIAL}

\section{Test setup}

The UAE trial (Jackson et al. 2005) utilized the following commercially available geosynthetics:

- A polyester staple fibre needle punched non woven

- A composite dual layer mixed denier needle punched non woven

- A split film high strength polypropylene woven
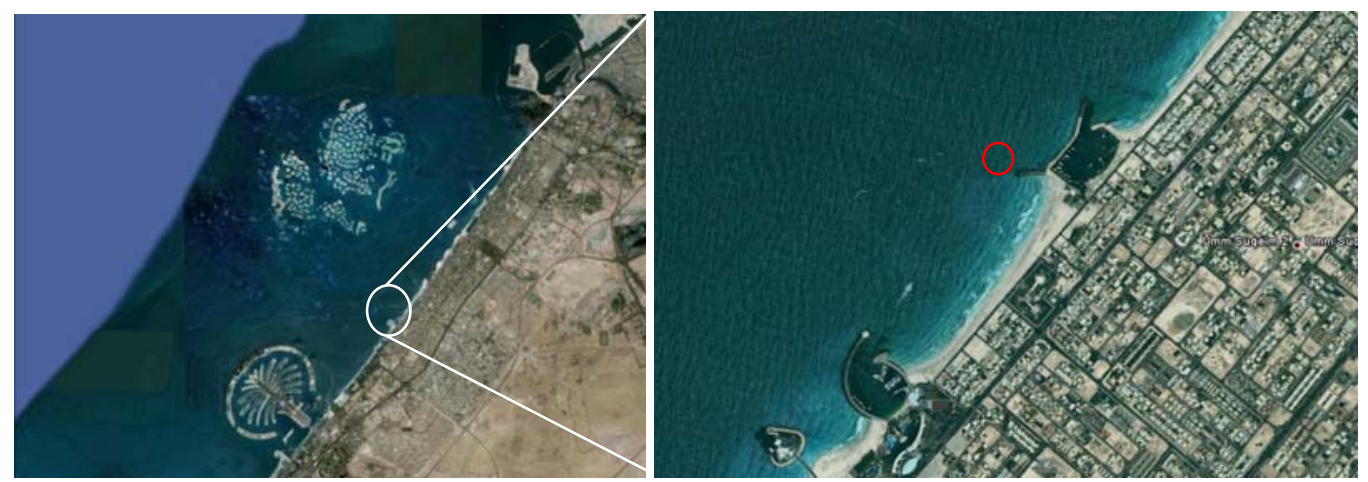

Figure 2. Location of deployment of UAE samples

Samples were deployed in Dubai (United Arab Emirates) on a navigation beacon within the Gulf at two different depths. Samples were placed in March 2005 and retrieved in July (after 4 months) and November (after 8 months).

\section{Results}

The results showed that there was considerable difference between the growth on the woven and non-woven samples. The non-woven samples tended to promote soft growths, with an initial dominance of macro-algae and later development of sponges and ascidians (sea squirts). The woven sample was dominated by bivalve / mollusk growth. This type of "hard" growth was similar to observations of growth on rock and other conventional structures in the vicinity of the trial and the pile to which the samples were attached.

The non-wovens showed a much higher biodiversity and productivity than the woven sample, particularly the composite non-woven, which supported crabs, annelids, polychaetes and shrimp after only 4 months.

The full results are presented by in a separate paper by Jackson et al (2005). 


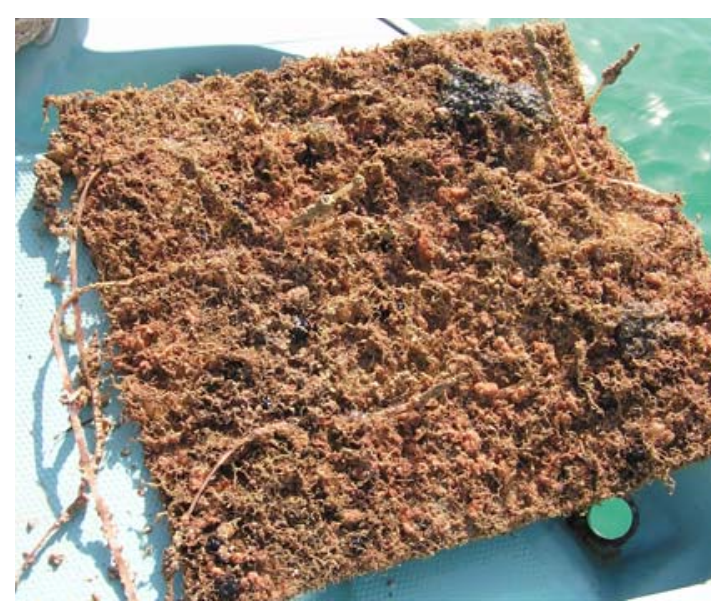

Figure 3. Non-woven composite sample after 4 months

\section{Discussion}

The trial confirmed that, even in the hot, high salinity conditions of the Gulf, geosynthetics can still provide an effective substrate for marine growth and that the type of geosynthetics used determines the type of growth. Similar to other trials, the woven geotextiles supported "harder" growths which were considered to be unsuitable for coastal structures where recreational benefits might be encouraged. While both non-woven geosynthetics provided improved habitat suitable for recreational usage, the composite layer geosynthetic provided the most diverse habitat.

\section{AUSTRALIA TRIAL}

\section{Test setup}

For the Gold Coast (Australia) trial, four different geosynthetic materials were chosen (Figure 4).

- A polyester staple fibre needle punched non woven (ELCOMAX $\left.{ }^{\circledR} 1200 \mathrm{R}\right)$

- A composite dual layer mixed denier needle punched non woven (ELCOMAX® 1209RP)

- A staple fibre woven geosynthetic (Grassroots)

- A composite of heavy-duty polypropylene fibres with a thin backing layer of polyester / polypropylene fibre geotextile (Drainmat)

The ELCOMAX ${ }^{\circledR} 1200 \mathrm{R}$ and 1209RP are standard products that have been successfully utilized in coastal structures (including the Narrowneck artificial reef). The Grassroots and Drainmat products had not been previously trialed and are designed primarily for turf reinforcement and drainage respectively, but both geosynthetics have an open structure that was expected to provide a suitable substrate. A woven type geosynthetic was not included due to its poor performance in other trials. The samples were compared to the concrete marina piles to which the samples were attached. The samples were secured around the pile using cable ties with the more complex or "open" side away from the pile.

The trial location was within the calm waters of the Gold Coast Broadwater. Samples were placed at two locations within the Southport Yacht Club marina (close to the channel and close to the shore). The difference between the two sites was the exposure to waves and currents (and associated water quality). Samples were deployed at two depths, $-2.5 \mathrm{~m}$ LAT ( $1 \mathrm{~m}$ above the seabed) and $-1 \mathrm{~m}$ LAT (just below the pontoon).

The samples were placed in April 2006 and retrieved in February 2009 after an almost 3 year deployment. It is noted that retrieval occurred during the summer period. 
4
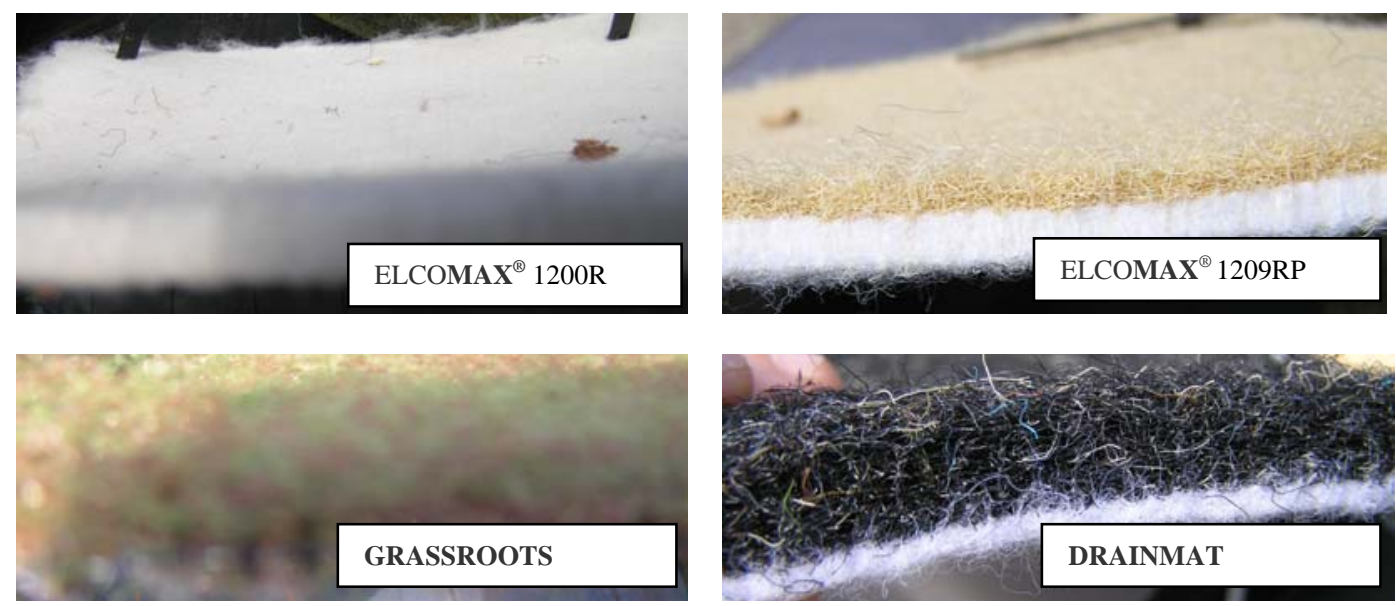

Figure 4. Geosynthetic 300mm square samples (ELCOMAX 1200R, ELCOMAX 1209RP, Grassroots, Drainmat)
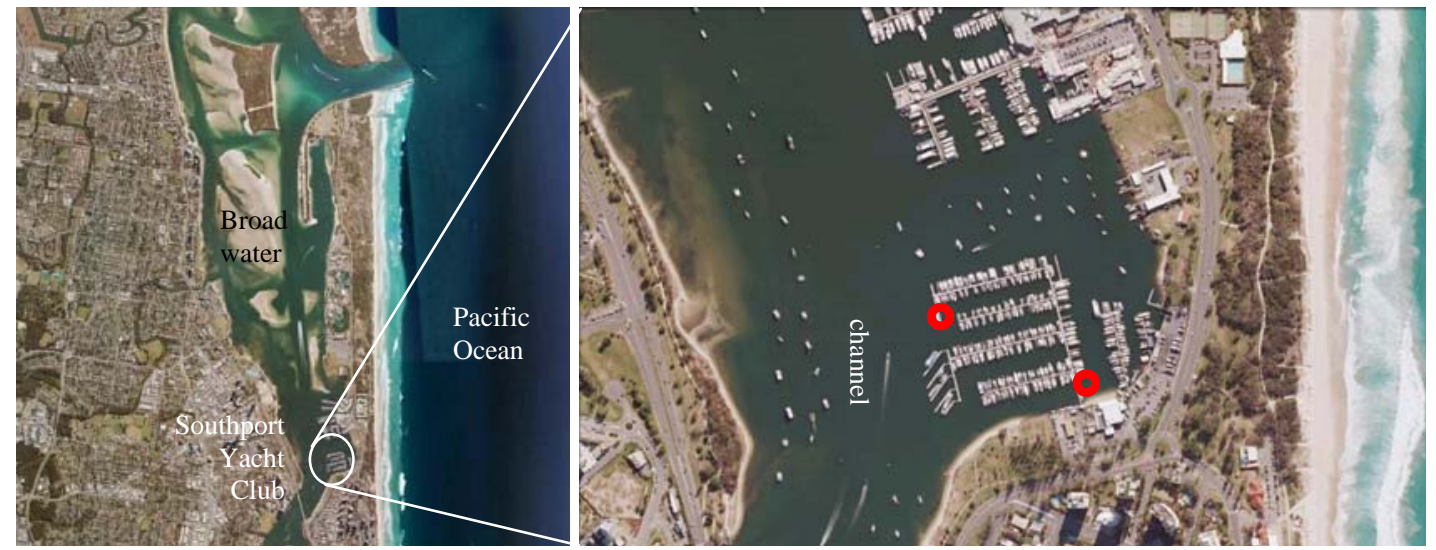

Figure 5. Location of deployment of Australian samples

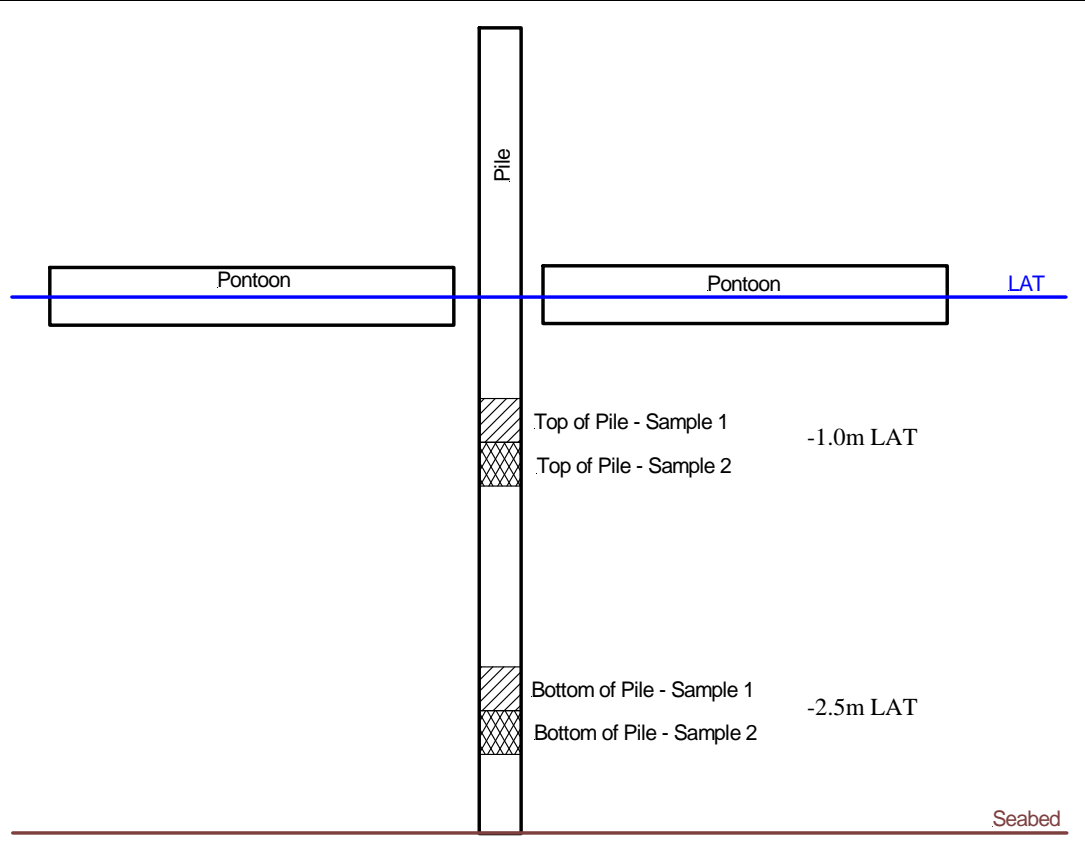

Figure 6. Configuration of sample deployment 


\section{Results}

After 3 years deployment, there was substantial growth on all the samples. While the piles were dominated by oysters or barnacles, there was a predominance of a range of "soft" growths on the geosynthetics, including sponges, algaes, ascidians (sea squirts) and anthozoa. Bivalves and oysters were also present on some samples, but these were predominantly on the edges or back of the sample (adjacent to the pile) and would not be expected to be present on a structure.

There were a range of species present, including:

- Worms

- Nudibranch
o Tubeworm
o Roundworm
o Fan worm
o Flat worm
o Polychaete worms

- $\quad$ Crabs (Mud crabs and Portunid crabs)

o Megalopa (final larval stage)

o Juvenile crabs

o Adult crabs

- Prawns
o Juvenile prawns

o Adult prawns

- Shrimp

- Brittlestars

- Seaspider

- $\quad$ Fish (gobi)

\section{Impact of Geosynthetic type}

All geosynthetic samples developed "soft” growth suitable for contact during recreational usage. In general, the composite 1209RP and Drainmat samples exhibited the greatest coverage of growth. They also displayed higher numbers and diversity of other species in comparison to the Grassroots and 1200R. This was anticipated as the open structure of the geosynthetic outer layer has greater overall surface area and the voids provide greater habitat complexity and protection during the initial growth stages.

It was also noted that the Grassroots sample deteriorated substantially during the long trial period and its suitability in long-term coastal applications appears to be limited.

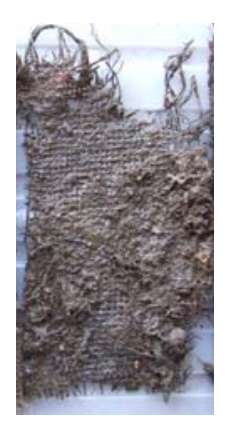

Figure 7. Deteriorated Grassroots sample

\section{Impact of Water Depth}

The shallower samples would likely experience greater exposure to light being closer to the surface (despite shadowing from the pontoon) and lower turbidity being further from the seabed. As could be expected, top samples for both locations exhibited a greater coverage of algaes (for outer pile, four times that of the bottom samples). The bottom samples experienced a greater ingress of fine material from the seabed. 


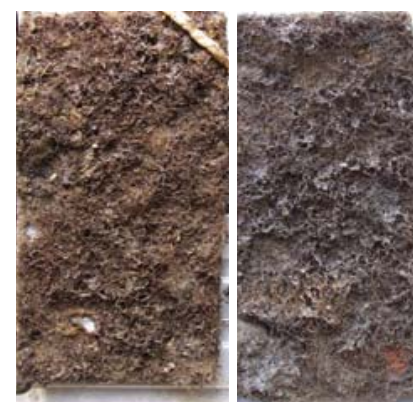

Figure 8. Samples from (a) top of outer pile and (b) bottom of outer pile after removal of major growth

\section{Impact of Water Flow}

The outer pile experienced higher currents (and possibly correspondingly improved water quality). For the concrete piles, the higher flow allows a predominance of barnacle growth (filter feeders) compared to the inshore pile which is dominated by oysters (which are capable of feeding in lower flow conditions). The samples on the outer pile experienced much higher growth (25 - 100\% coverage) than the samples in calmer water (10 - 35\% coverage). In general, species diversity on the outer pile was approximately double that of the inshore pile.

\section{COMPARISON}

Unlike the UAE samples (which were retrieved after a much shorter period), the Australian samples were left in over a longer timeframe and were retrieved in summer after almost three years (Figure 9). Conditions between the two sites were also very different. It is clear that geosynthetics can support significant growth and habitat in a wide range of the conditions. Regardless of location, nonwoven geosynthetics appear to support a dominance of "soft" type growths which are considered most suitable for structures where recreational aspects of the structure are desirable. While the overall performance of the geosynthetics differs depending on conditions, the geosynthetics with a more "open” structure consistently provide greater productivity and diversity of growth and resident species.

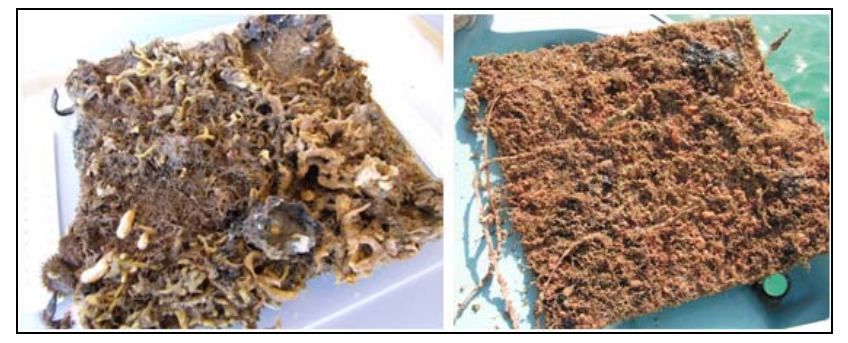

Figure 9. ELCOMAX 1009RP after (a) 3 years, Gold Coast and (b) 4 months, UAE

\section{CONCLUSION}

The comparison of trials at both sites and observations of growth on actual sand-filled geotextile structures were generally consistent. For design, selection of the most suitable geosynthetic is essential. This will depend on a number of factors, including the importance of environmental benefits, local conditions and anticipated usage. Where ecological performance is an important aspect, deployment of samples in the specific location will provide a site-specific indication of performance of various geotextiles. It is generally considered that high strength non-woven type geosynthetics are most suitable for structures which are intended to provide ecological / recreational benefits as they provide higher diversity and less hard growths which are not as user-friendly. To further increase diversity, consideration should be given to selection of a geosynthetic with a more open structure [e.g. composite type geotextiles that have a "hairy" outer layer with significant voids].

\section{ACKNOWLEDGMENTS}

Geotextile samples tested as part of the Australian trial were provided by Geofabrics. 


\section{REFERENCES}

Edwards, R. 2003. An investigation into the biodiversity of a geotextile artificial reef, Narrowneck, Gold Coast, Qld. University of New England Honours Thesis

Jackson, L.A. 2010. Design and Construction of low crested reef breakwaters using sand-filled geotextile containers. Geosynthetics and Modern Materials in Coastal Protection and Related Applications. IAHR

Jackson, L.A., Restall, S., Corbett, B.B. and Reichelt, R.E. 2005. Monitoring of Geosynthetics in Coastal Structures, Proceedings of $1^{\text {st }}$ International Conference in Coastal Zone Management and Engineering in Middle East

Jackson, L.A., Reichelt, R.E., Restall, S., Corbett, B., Tomlinson, R. and McGrath, J. 2004. Marine Ecosystem Enhancement on a Geotextile Coastal Protection Reef - Narrowneck Reef Case Study. Proceedings of the $29^{\text {th }}$ International Conference on Coastal Engineering. ASCE 